\title{
New Ideas of College Students' Management under the Mode of University-enterprise Cooperation
}

\author{
Xuezhang Bu \\ Sichuan Information Technology College, Guangyuan 628017, China. \\ buxuezhang@163.com
}

\begin{abstract}
University-enterprise cooperation is an important way to realize the cultivating goal of higher vocational education. This paper discussed that in constructing university-enterprise cooperation personnel training mode, higher vocational colleges should draw lessons from enterprise of the management and requirements for staff to strengthen students' education and management and make higher vocational students feel the enterprise atmosphere in advance. In the "real work environment", it can improve the ability effectively and shorten the period of adaptation when in the job, which is one of the university and enterprise win-win model.
\end{abstract}

Keywords: Student management; university-enterprise cooperation; student education.

\section{Introduction}

University-enterprise cooperation refers to on the mode of running education level, schools and enterprises hand in hand to innovate educational system and associate with society, enterprise and industry, namely combining with the enterprise to be an entity. Its purpose is that in the whole process of talent training, it comprehensively cultivates students' vocational quality and technical application ability and the employment competitive power and make full use of the school and the enterprise two different education environment and education resources to combine theoretical study, basic skill training in school with practical work experience enterprises through two-way intervention of schools and enterprises. It makes the students with a certain working experience and experience as well as certain social adaptation ability when they leave school and engage into the career. It also lets the student taste the real flavor as a professional person in school before they become real employees and let them learn how to be a person, how to do things in the real work environment[1].

\section{Changes of Student Management under University and Enterprise Cooperation Mode}

\subsection{Dual Identity Causes Unbalanced Mentality.}

When students in the school, their identities are students, but when they take internship in enterprise, their identities become workers. Different identity results in psychological and physiological changes. Psychologically, first of all, school life environment is relatively simple, teachers takes teaching as the foundation and treat students relative tolerant while in enterprise, there are strict enterprise standard requirements and strict management, students may find it difficult to adapt to a certain extent. Secondly because the profession is not necessarily completely consistent, what they have learned in school is not necessarily completely agreed to enterprises operation, which can also lead to resistance mood to a certain extent. Physically, today's students have less physical exercise and school life is more relax but in the enterprise, there are more physical labor workload, working pressure, their body may unable to stand. Thus, it is easily to cause unbalance mentality of students.

\subsection{Dual Subjects Causes out of Control of Student Management.}

In the mode of university-enterprise cooperation, the management subjects are not only school but it transforms into school and enterprise. They interactively complete teaching and management tasks, therefore the subjects of student management work also become double subjects. Because duties boundaries in the teaching, student management, process monitoring, effective assessment are not clear, it makes two sides cannot implement comprehensive and effective management to the student. 
School teachers are not familiar with the enterprise and limits by their own tasks of instructors in enterprises and the lack of professional training on teaching education, both can't undertake the student management work effectively, which causes out of control of student management to a certain degree.

\subsection{Complex Environment Causes Disorder of Student Life.}

Although school is no longer an ivory tower, but the living environment is relatively simple, after school life is relatively rich while enterprise life relatively drab and people pay more attention on the use of skills training. At school, as long as they work hard, interpersonal relationship is relatively simple, but the enterprises pay more attention on communication with people and team collaboration. At school, although some schools have pay attention on the infiltration and training of enterprise culture, but there are a lot of campus culture and enterprise culture differences. Face environment change of life, study and work, students often do not have a corresponding preparation leading to disorder of the students' life.

\section{New Idea of Student Management under the Mode of University-enterprise Cooperation}

\subsection{Take Student as the Foundation.}

When students takes the enterprise practice, they experience transition of students and social people and their mentality, living environment change a lot. Because of the different awareness on the enterprise and society and their different personality, it leads to different reactions when facing the same changes. At this time, students need management staff make a different response patiently and carefully according to different individuals to fully respect students' personality and guide students taking a concern, understanding and tolerant attitude. At the same time, they need to stimulate students' subjectivity, encourage students to participate in student management, improve the ability of self-management and safeguard their own benefits.

\subsection{System Innovation.}

System is the basis of university-enterprise cooperation. It's crucial to improve related student management system in university-enterprise cooperation mode and strengthen the cohesion between schools and enterprises. For school, it must emphasizes vocational education in school education, penetrate the enterprise culture in the campus culture and take enterprise management system for reference in school management. For enterprises, it should attach importance on the fundamental difference between intern students and staffs and consider the both needs of enterprise production and education teaching and take appropriate school student management experience for reference to do a good management. At the same time, it should establish management mechanism and gradually improve the management measures and make sure management responsibilities according to different situations. In this way, it can reduce students' maladaptation resulting from environment and the mentality change and do a more reasonable, comprehensive and effective management work [2].

\subsection{Flexible Management.}

At school, student's identity is a student and they should pay more attention on theoretical achievement while in the enterprise, students are employees, the focus transforms into the improvement and advancement of skills and collaborate abilities. On the other hand, during the internship, for schools, students have not graduated but they are not in school; for enterprise, students is on-the-job but they are not formal employees. Just because of the interaction management of school and enterprise, the student's environment is relatively complex, so student management work don't have fixed mode and need to vary according to the specific circumstances. The scale of the assessment and standard should change according to the circumstance. That is the flexible management [3]. 


\subsection{Technology Updating.}

21 st century is the era of information technology, after 90s students are mostly interested in the Internet and they are able to skillfully use network technology. Therefore the student management work should utilize the method of network information technology to strengthen and improve management level as soon as possible. For instance, in management, it can establish student information database to realize the student teaching, training, evaluation of information sharing and strengthen information feedback to ease the burden on the management staffs so as to improve the management efficiency and level. In terms of communication, for example, it can through the establishment of QQ group, WeChat, fetion, campus web pages, and so on, to promote the communication between students and teachers and improve the interaction frequency and strengthen the pertinence and effectiveness of the work.

\section{Summary}

Build the model of cooperation between enterprises and schools, in the process of school education and management, it should draw lessons from requirements for the management of the staff in the enterprise to innovate, improve the content of the education and management, reform methods so it can combine school education and management with enterprises' requirement and demands for staffs to truly become high-skilled talents in the real work environment.

\section{References}

[1] Lin Wang. The exploration of work-integrated learning, cooperation between schools and colleges mode [J].Higher vocational education teaching reference, 2010, (12).

[2] Xueseng Du. Operation method of work-integrated learning talents cultivation mode [J]. Tianjin binhai education, 2010 (1).

[3] Biao Chen. Student education management countermeasures under university-enterprise cooperation $[\mathrm{J}]$. Journal of fujian institute of education, 2010 (2). 